\title{
DECOCCIÓN 'AMPUTACIÓN': UNA ACEPCIÓN FANTASMA EN EL DICCIONARIO DE LA REAL ACADEMIA ESPAÑOLA*
}

JAVIER RODRÍGUEZ MOLINA

Instituto de la Lengua Española. CSIC

Sometido a constantes revisiones, y tras una larga historia editorial, el Diccionario de la Real Academia Española (DRAE) no está exento de las veleidades que la tradición textual acarrea, ya que en la compilación, redacción y actualización de un diccionario como el DRAE es inevitable y natural que se deslicen enrores, erratas y acepciones fantasma. Tarea propia de filólogos (iy lexicógrafos!) es dar cuenta y cumplida advertencia de estos errores. El lema decocción presenta en la última edición del diccionario académico ${ }^{1}$ tres acepciones (1), la última de las cuales, en mi opinión, reviste un carácter espurio, como trataré de poner de manifiesto en las breves líneas que siguen.

1) Decocción. (Del lat. decoctio, -ōnis) f. Acción y efecto de cocer en agua sustancias vegetales o animales. I| 2. Producto líquido que se obtiene por medio de esta DECOCCIÓN. II 3. Med. p. us. Amputación de un miembro o de cierta parte del cuerpo.

* Esta investigacion ha sido financiada gracias a una beca FPU (AP2002-0363) de la Secretaría de Estado de Universidades. Quede constancia aquí de mi agradecimiento a Pedro Álvarez de Miranda y a Leonardo Gómez Torrego, por las valiosas sugerencias que me han hecho a propósito de este trabajo.

I Real Academia Española, Diccionario de la Lengua Española. Vigésima segunda edición 2001, Madrid, Espasa Calpe, 2001. No me consta que la RAE tenga previsto modificar este lema en la próxima edición, según la consulta efectuada en el sitio web de la Academia (http:// www.rae.es) con fecha 24/02/2005. María Moliner, Diccionario de uso del español, $2^{2}$ edición, Madrid, Gredos, 1998 [1. ed. de 1966] recoge también estas tres acepciones ( $\mathrm{y}$ a todas les asigna la marca culto o cientifico). El DEA (Manuel Seco, Olimpia Andrés y Gabino Ramos, Diccionario del Español Actual, Madrid, Aguilar Lexicografía, 1999) únicamente recoge las dos primeras acepciones del DRAE.

RFE, LXXXV, 2005, 1. , págs. 159-164 
Dicho lema aparece ya recogido en el Diccionario de Autoridades ${ }^{2}$ tal como se muestra en (2). Como puede observarse, el significado de este vocablo aludía fundamentalmente a la digestión de los alimentos, entendida (según la medicina de la época) como cocción del alimento.

2) DeCoccion. $r$. f. El efecto de cocerfe ò ef tar cocida alguna cofa. Comunmente fe dice de la digeftión que hace el ef tómago de la vianda ó mantenimiento. Viene del latino Decoctio, que fignifica efto mi fmo.

No es hasta las ediciones de 1843 (3) y 1884 (4) cuando la definición de esta voz adquiere una configuración similar a la que presenta hoy el DRAE en sus dos primeras acepciones, puesto que el significado de 'digestión' en la definición de decocción desaparece de los diccionarios académicos en 1843, edición que ya no recoge este significado ${ }^{3}$. La edición de 1843 es también la primera que recoge el significado de la primera acepción que consta hoy en el DRAE, mientras que la segunda acepción registrada por el DRAE aparece por vez primera en la $12^{a}$ edición (1884). Ambas acepciones cuentan con numeroso respaldo documental, desde el otoño de la edad media hasta nuestros días ${ }^{4}$.

${ }^{2}$ Real Academia Española, Diccionario de la lengua castellana, Madrid, Francisco del Hierro, 1726-1739, 6 vols. (Cito por la ed. facsímil Diccionario de Autoridades, Madrid, Gredos, 1963, 6 tomos en 3 vols. El volumen que nos interesa, el de la letra D, es el tomo tercero, publicado en 1732). También el Diccionario de Terreros (Esteban de Terreros y Pando, Diccionario Castellano con las voces de ciencias y artes, edición facsímil, Madrid, Arco/Libros, 1987, tomo I, s.v. decocción [editado en 1786, aunque la obra ya estaba acabada en 1767]) presenta este lema.

${ }^{3}$ Documentalmente, el significado de 'digestión' que da Autoridades no sobrepasa los siglos de oro. Veamos algunos ejemplos: orificio es aquella parte por donde se inundan, exoneran y expelen las inmundicias interiores que restan de la decocción del mantenimiento (Vicente Espinel, Vida del escudero Marcos de Obregón, edición, introduccion y notas de M.' Soledad Carrasco Urgoiti, Madrid, Castalia, 1972, I, pág. 122 [1618]; ejemplo citado por Autoridades); pues los manjares con que / a tu parecer, sustentas el cuerpo (y es así) / en su decocción, por otra parte, gastan el ca- / lor natural, que es tu vida, con el trabajo de / disponerlos (Francisco de Qusevedo y Villegas, La Cuna y la Sepulura. Para el conocimiento propio y desengaño de las cosas agenas, edición crítica, prólogo y notas de Luisa López Grigera, Madrid, Anejo XX del $B R A E, 1969$, cap. I, v. 84, pág. 26 [1630-1633]). Véanse también los ejemplos citados por el Diccionario de textos médicos antiguos, bajo la diresción de M." Teresa Herrera, Madrid, Arcol Libros, 1996, 2 vols., s.v. decocción.

4 Citaré algunos ejemplos: $e$ si el vapor seco sotil fuere bien mezclado con el humjdo \& falleciere dela decoçion \& aya estado en lugar muy frio estara en forma de argenbivo (Alfonso de la Torre, Visión Deleytable, edición crítica y estudio de Jorge García López, Salamanca, Edjciones Universidad de Salamanca, 1991, fol. 36v [c. 1440]); mas en las aguas que fierven de suyo, / por venas sulfüreas faziendo pasada/ la tal decocción fue conglutinada (Juan de Mena, Laberinto de Fortuna, edición de Maxim Kerkhof, Madrid, Castalia, 1997, estrofa 244 [1444]); dicen que para esto vale mucho la decocción hecha con vino cocido con el nido de las avispas (Damián Carbón, Libro del arte de las comadres o madrinas, del regimiento de las preñadas y paridas, y de los niños, transcripción de Francisco Susarte Molina, Alicante, Universidad de Alj- 
3) DeCCOCion. n. El acto y efecto de cocerse ó estar cocida alguna cosa. Comunmente se usa hablando de plantas medicinales. Concoctio.

4) Decocción (Del lat. Decoctǐo.) f. Acción y efecto de cocer en agua sustancias vegetales 6 animales. It Producto líquido que se obtiene por medio de la decocción.

En cuanto a decocción 'amputación de un miembro o de cierta parte del cuerpo', hace su aparición en la 16. ${ }^{a}$ edición del DRAE (1936/39), y como tal se ha mantenido hasta la edición actual (2001). Sin embargo, dos hechos me hacen sospechar de la legitimidad de esta acepción. En primer lugar, esta no se ve refrendada por apoyo documental, o al menos yo no he podido hallarlo. En segundo lugar, el propio contenido semántico de la definición disuena de las dos acepciones anteriores, semánticamente afines.

Considero que la respuesta a este enigma puede hallar cumplida respuesta en la propia historia del DRAE. En la edición de 1791, la Academia incorpora al diccionario la voz decolacion, ${ }^{5}$ con la siguiente definición y la marca ant.: 'lo mismo que degollación'. Desde 1822 hasta 1992, bajo la voz decolación, el DRAE remite siempre a degollación (puesto que decolación en su acepción 'decapitación', 'cortar la garganta' no es más que la forma culta de degollación). Con este sentido de degollación ('decapitación', 'separación de la cabeza del tronco', 'corte de la cabeza por la garganta o el cuello', etc.) aparece usada la palabra decolación en los pocos textos en los que se documenta, ya que se trata de una voz muy poco frecuente ${ }^{6}$.

cante, 1995, I, cap. XLVII, pág. 125 [1541]); esta comun aceptación le proviene de que la preparación que le hacen con la decoccion, en que humedecen sus hojas al tiempo de juntarlas (Antonio de Ulloa, Viaje a la América meridional, edición de Andrés Saumell, Madrid, Historía 16, 1990, Lib. VI, cap. 4, § 865, pág. 460 [1748]); Estas sustancias pueden ser la goma adraganto, el engrudo de almidon, la decocción de nuez de agalla, el azúcar de leche, y, sobre todo, la goma arábiga (Justo Zapater y Jareño y José García Alcaraz, Manual de litografía, con un estudio bibliográfico de Juan Carrete Parrondo, Madrid, CLAN, 1993, pág. 91 [1878]); el escaramujo se consume en infusión, decocción, polvo jarabe, mermelada, confitura o licor (Maurice Mességué, Mi herbario de salud, trad. de Ana M.* de la Fuente, Barcelona, Plaza Janes, 1985, pág. 134); Otras fórmulas eran ricas en decocciones de plantas como el ajenjo, el hisopo, la ruda (...) (José M.. Massons, Historia de la Sanidad Milizar Española, Barcelona, Ediciones Pomares-Corredor, 1994, tomo II, pág. 368).

${ }^{5}$ El Diccionario de Autoridades no trae la voz decolación, pero sí el lema degollación. Esta voz decolación, todavía presente en el diccionario en 1992, desaparece del DRAE en la $22^{*}$ ed. (2001). El DEA no registra el lema decolación, pero sí degollación 'acción de degollar (cortar el cuello)'. María Moliner (tanto en la edición de 1966 como en la de 1998) sí que registra decolación como lema con entrada propia, remitiendo a degollación. Además, también recoge decolación como sinónimo de 'degollación' s.v. degollar 'ejecutar, matar' en su 2." edición.

${ }^{6}$ Los ejemplos existentes son muy escasos: véase el Diccionario de textos médicos antiguos, op. cit. s.v. degollación. Alguno de época moderna: En una palabra, no queremos exponernos a morir por decolación como el Partido Civil (Manuel González Prada, Horas de Lucha, edición de Luis Alberto Sánchez, Caracas, Biblioteca Ayacucho, 1976, pág. 213 [1898]). El verbo de- 
Pues bien, la acepción 'amputación de un miembro o de cierta parte del cuerpo' que el DRAE ubica en el lema decocción corresponde propiamente, en mi opinión, a la voz decolación. Se trata de una correspondencia que no solo se debe a la notable (y explicable) afinidad semántica entre esta definición y la del lema decolación 'degollación', sino que también encuentra un punto de apoyo inestimable en las siguientes pruebas documentales (5-7):

5) Antes de media noche contaba Muñiz en un corro de amigos, entre los cuales se encontraba Santiago Ibero, que él, por sí y ante sí, después de presenciar la cura del herido, había visitado al primer operador de España, don Melchor Sánchez Toca. Y oídas las impresiones del amigo, opino el maestro que urgía la inmediata decolación del brazo izquierdo. De esto trataron los íntimos; pero ninguno se atrevió a proponer el caso a la familia, pues a la Condesa de Reus se había dicho que las heridas no eran de 'muerte, y la Facultad no consideraba precisa la intervención quirúrgica $(. . .)^{7}$

6) Finalmente describe su casuística que empezó en enero de 1848 y que fue la siguiente:

[...]

Decolación del primer dedo del pie (Jerónimo Roure)

Amputación del brazo (Jerónimo Roure) ${ }^{8}$

7) La decolación cervical con tijeras de Dubois o Siebold o con el decalotomo de Frascano parece ser menos peligrosa que una cleidotomía [hablando de cómo extraer un feto muerto del útero] ${ }^{9}$

Los diccionarios de otras lenguas nos brindan también otro interesante punto de apoyo: por un lado, bajo la voz equivalente a decocción recogen únicamente un elenco de acepciones idénticas a las dos primeras acepciones del DRAE (pero no muestran ni rastro de la tercera acepción que el DRAE propor-

colar, sin embargo, se documenta desde mucho antes, puesto que aparece ya en las Glosas Silenses (cf. Léxico hispánico primitivo (siglos VII al XII), proyectado y dirigido inicialmente por Ramón Menéndez Pidal, redactado por Rafael Lapesa con la colaboración de Constantíno García. Edición al cuidado de Manuel Seco, Madrid, Fundación Ramón Menéndez Pidal y Real Academia Española, 2003, s.v. decolare).

${ }^{7}$ Benito Pérez Galdós, España Trágica, Madrid, Alianza, 1986, cap. XXIX, pág. 199 [1909]

${ }^{8}$ José M. Massons, Historia de la Sanidad Militar Española, cit., tomo III, págs. 393-394.

9 Juan Rodríguez Argielles y Rubén H. Saldaña García, PAC GO-1. Programa de Actualización Continua para el Ginecoobstetra. Libro 4. Obstetricia. El parto operatorio, México D.F. Intersistemas, 1998, LSBN 970-655-078-X (http://www.drscope.com/pac/gineobs/o4/o4_pag36.htm). Tomo este texto de la versión digital del libro citado, ya que me ha sido imposible hacerme con el texto impreso. 
ciona en el lema decocción); por otro lado, bajo la voz equivalente a decolación (decolation en el caso del inglés, décolation en el caso del francés) registran, además de la consabida acepción 'decapitación', una segunda acepción en la que decolación significa «Spéc. MÉD. Section du cou d'un foetus mort, practiquée in utero pour faciliter son extraction» ${ }^{10}$, «spec. in Obstetric. Surg., severance of the head from the body of a foetus» ${ }^{11}$. Volviendo al español, los diccionarios médicos modernos que recogen el lema decolación dan justamente esta definición 'amputación de un miembro...', 'decapitación' bajo la voz decolación y no en decocción, o bien hacen a esta voz decolación sinónima de decapitación o de degollación ${ }^{12}$. Como puede observarse, los ejemplos aducidos (tanto ejemplos textuales como el testimonio de otros diccionarios) resultan sumamente reveladores, y nos compelen a calificar como 'acepción fantasma' la definición «amputación de un miembro o de cierta parte del cuerpo» que el DRAE sitúa bajo la voz decocción.

Tan sólo resta dar cuenta de la génesis de este lapsus. El DRAE incorpora la acepción citada 'amputación de un miembro...' bajo la voz decocción en la decimosexta edición (1936/39). Desde 1791 ( $3^{\mathrm{a}}$ ed.) hasta 1947 (17 $\mathrm{ed}$.) decocción y decolación eran voces contiguas. Mi intuición es que, en realidad, la Academia pretendía incorporar dicha acepción bajo la voz decolación, como parece (y probablemente les parecería a los redactores de 1936) lo correcto, pero por un capricho del destino (o de las vicisitudes del proceso de imprenta, vaya usted a saber) la citada acepción fue a parar, por error, al lema decocción. No olvidemos que en 1936/39, cuando el DRAE incorpora la acepción 'amputación de un miembro o de cierta parte del cuerpo' bajo la voz decocción, decocción y decolación eran lemas físicamente contiguos en la macroestructura del Diccionario, hecho que hace perfectamente explicable el deslizamiento de la acepción citada de un lema a otro. Luego, el progresivo distanciamiento de los lemas decocción y decolación desde 1947 por la incorporación de voces nuevas y la supresión de la entrada decolación en 2001 han oscurecido, a mi

${ }^{10}$ Trésor de la langue française, Dictionnaire de la langue du XIXe et du XXe siècle (I7891960), publié sous la direction de Paul Imbs, Paris, CNRS, 1978, tomo 6, s.v. décollation. Atestiguan este uso médico đe décollation desde 1892. Más o menos la misma definición presenta también el Dictionaire historique de la langue française, sous la direction de Alain Rey, Paris, Le Robert, 1992, s.v. décollation.

"The Oxford English Dictionary, second edition, prepared by J. A. Simpson and E. S. C. Weiner, Oxford, Clarendom Press, 1989, vol. IV, s.v. decollation. Muy interesante para la hipótesis que vengo defendiendo resulta la primera definición ( $\mathrm{y}$ los ejemplos textuales citados) que este diccionario proporciona s.v. décollement: «Med The process of separating organs or tissues from surrounding parts; also the state of being thus separated». Como puede observarse, esta definición se corresponde con la $3 .^{*}$ acepción que el DRAE proporciona (erróneamente, en mi opinión) s.v. decocción.

12 Cf. Diccionario teminológico de ciencias médicas, Barcelona, Salvat, 1968, 10." edición [1." ed. de 1918], s.v. decocción y s.v. decolación. 
modo de ver, el proceso que acabo de reconstruir, y han dificultado la correcta apreciación de este gazapo. Mientras el lema decolación estaba presente en el DRAE, aún era posible percatarse del enor y establecer una conexión lógica entre 'amputación de un miembro' y la voz decolación. Dado que la última edición del DRAE (2001) ha suprimido esta entrada, actualmente es imposible detectar la mencionada acepción fantasma que, de no corregirse, no hará sino perpetuarse a lo largo de las sucesivas ediciones del diccionario académico.

$\mathrm{Si}$ mis argumentos son correctos, considero que no hay motivo para seguir manteniendo la acepción 'amputación de un miembro o de cierta parte del cuerpo' s.v. decocción. Se trata de una acepción fantasma originada por un error fácilmente explicable en la transmisión y elaboración textual del DRAE. La recuperación o no del lema decolación para reubicar correctamente la citada acepción es una decisión que compete a la Real Academia, que sin duda sabrá aplicar, como hasta ahora ha venido haciendo, el mejor de los criterios. 